\title{
CONEXÕES POLÍTICAS E AS EMPRESAS BRASILEIRAS: UM ESTUDO EXPERIMENTAL SOBRE AS DECISÕES DE INVESTIMENTO NO MERCADO DE CAPITAIS ${ }^{1}$
}

João Marcelo Alves Macedo César Augusto Tibúrcio Silva ${ }^{3}$ Márcio André Veras Machado ${ }^{4}$

Resumo: A economia brasileira sempre dependeu da força do Estado, que, por meio de sua capacidade de investimento, alavancava certos setores. Na década de 1990, com os movimentos privatizadores e a escassez do poder investidor/gestor do Estado, as organizações buscavam formas de se financiarem. Surgiram as conexões políticas, meios de interligação de empresas ou grupos econômicos aos governos, que se dão pela estrutura de propriedade, por doações a campanhas e pelas ligações dos membros do board ou do conselho de administração com os governos. Este estudo tem a seguinte questão de pesquisa: estariam os analistas propensos a manterem, na sua carteira de investimentos, empresas que têm conexões políticas explícitas? Para tanto, utilizou-se do método indutivo, mediante uma abordagem quase-experimental, onde os respondentes recebiam novas informações e eram questionados sobre a manutenção da empresa no portfólio. A população foi de professores, estudantes e outros profissionais, das áreas de ciências contábeis, administração, economia e afins, que totalizaram 408 respondentes, sendo que a amostra finalizou com 308 respostas. Utilizou-se para análise uma regressão logística, com os testes de Hosmer e Lemeshow e de Count $\mathrm{R}^{2}$ e, complementarmente, crosstabs de dados característicos dos respondentes. Os resultados apontaram para um público apolítico predominante e as variáveis: (a) classificação política (CLAS); (b) filiação partidária (FIL); e (c) indicar a empresa sem conhecimento da conexão (IND) são significativas a 10\% para o modelo. Ao final, chegou-se à conclusão de que a conexão política não é percebida pelas imagens de interações de políticos e empresários, mas pelas informações da mídia em geral, como, também, que as variáveis que influenciam a manutenção de uma empresa conectada são: percepção da classificação política e filiação partidária do respondente, e o fato de se ter indicado a empresa para participar do seu portfólio antes.

Palavras-chave: Conexões políticas. Mercado de capitais. Decisões de investimento. Teoria portfólio comportamental.

\footnotetext{
Artigo aprovado e apresentado no XIV Congresso USP de Controladoria e Contabilidade em 2014

2 E-mail: jmmarcelopb@gmail.com - UFPB - Universidade Federal da Paraíba

${ }^{3}$ E-mail: cesaraugustotiburciosilva@gmail.com. Programa Multiinstitucional e Inter-regional de Pós-Graduaçăo em Ciências Contábeis - UnB/UFPB/UFRN

E-mail: mavmachado@hotmail.com. Programa Multiinstitucional e Inter-regional de Pós-Graduaçāo em Ciências Contábeis - UnB/UFPB/UFRN 


\title{
POLITICAL CONNECTIONS AND BRAZILIAN COMPANIES: AN EXPERIMENTAL STUDY ON INVESTMENT DECISIONS IN CAPITAL
}

MARKET

\begin{abstract}
Brazilian economy has always depended on the strength of State, which, through its investment capacity, leveraged certain sectors. In the 1990s, with the privatizers movements and shortages of investor/ manager power of State, organizations sought ways to finance themselves. Political connections emerged, interlocking means of companies or economic groups to governments, which are given by the ownership structure, by donations to campaigns and the connections of members of the board or the board of directors with government. This study has the following research question: would the analysts likely to remain, in its investment portfolio, companies that have explicit political connections? For this, the inductive method was used, through a quasi-experimental approach, where respondents received new information and were asked about the maintenance of the company's portfolio. Population was teachers, students and other professionals, from the areas of accounting, administration, economics and the like, which totaled 408 respondents, and the sample finished with 308 responses. For analysis, a logistic regression was used, with the Hosmer and Lemeshow and the Count $\mathrm{R}^{2}$ tests and, in addition, crosstabs of characteristic data of the respondents. Results pointed to a predominant apolitical public and the variables: (a) political classification (CLAS); (b) party affiliation (FIL); and (c) indicate the company without knowledge of the connection (IND) are significant at 10\% for the model. Finally, it was concluded that political connection is not perceived by the interactions images of politicians and business, but by media information in general, as also that the variables that influence the maintenance of a connected company are: perception of political classification and party affiliation of the respondent, and the fact of having indicated the company to join their portfolio before.
\end{abstract}

Keywords: Political connections. Capital market. Investment decisions. Behavioral portfolio theory. 


\section{INTRODUÇÃO}

O Estado sempre foi uma das forças motrizes mais pujantes para o desenvolvimento de um país ou região, o que se mantém até os dias atuais, e sua atuação gera incentivos que podem ser percebidos no crescimento da economia. Em alguns momentos, o Estado precisou atuar em frentes não privativas, ou seja, sua atuação não se restringiu aos serviços e áreas que são de sua atuação específica, daí o fato de inúmeros investimentos públicos serem nas chamadas empresas públicas, sociedades de economia mista e, mais recentemente, nas parcerias público-privadas.

Com o desenvolvimento da economia e a escassez de recursos públicos para investimentos, a busca por parceiros internacionais e, até mesmo, nacionais que financiem essas expansões é grande. Sabe-se que a economia brasileira passa por uma boa fase de crescimento, mesmo assim, algumas das mais pujantes empresas brasileiras possuem forte participação do Estado, de forma direta ou indireta, em seu quadro societário. Esse, por sua vez, pode ser um fator motivador ou, em igual proporção, desmotivador da atividade econômica, visto que a sua interferência, às vezes, leva às decisões econômicas pelo bem-estar social e não pelo seu cerne, que visa, na maioria dos casos, maximizar a riqueza das organizações e, consequentemente, de seus proprietários.

O crescimento da economia brasileira está atrelado a um cenário com fatores múltiplos, internos e externos e, em especial, políticas públicas voltadas a tal intuito. Entre os anos de 2000 e 2011 chegou-se ao crescimento médio anual de aproximadamente $4 \%$ a.a., esse patamar é superior as duas décadas anteriores. O período de maior crescimento se deu entre 2004 e 2011, atingindo uma média de 5,4\% a.a (Cruz et al, 2012).

O governo também influencia a economia, visto que é responsável pelo controle e/ou provimento de recursos financeiros, por meio da formulação de políticas públicas, e controla ou é proprietário das organizações. Entretanto, esse controle gera a dependência e o domínio do Estado sobre a atividade econômica como um todo (Camilo, 2011).

Alguns autores asseveram acerca da estrutura de propriedade das firmas e destacam duas dimensões importantes a serem observadas: (a) a concentração da propriedade; e (b) a identidade dos acionistas, sendo que tais análises são eminentemente voltadas para o acionista majoritário, uma vez que este detém um poder importante sobre a firma (Brey et al., 2011).

Pode-se, ainda, atribuir valor às organizações a partir de suas conexões políticas, a depender da estrutura de propriedade; logo, se a empresa é estatal ou privada, haverá possibilidades distintas de agregar valor com suas conexões. Verifica-se um maior valor para empresas que apenas têm laços com o governo, não sendo necessariamente integrantes de sua estrutura ou tendo sua participação direta (Wu, Wu e Rui, 2012).

Wu, Wu e Rui (2012) ainda alertam sobre o fato de que, quando o gestor integra a estrutura da organização estatal, a importância que a ele seria atribuída é diluída na propriedade do governo, uma vez que não precisará mais estabelecer a conexão, enquanto que nas organizações privadas, que têm na pessoa do diretor executivo (chief executive officer (CEO)) ou proprietário a conexão política e, com isso, não podem garantir um tratamento favorável às suas firmas por parte do governo, o valor imputado ao gestor conectado é individualizado. 
Lazzarini (2011) aponta que, no caso brasileiro, as conexões políticas e o que ele descreve como "capitalismo de laços" apresentam algumas disfunções e distorções; no entanto, seguem, em linhas gerais, o que se manifesta no mundo. Segundo o autor, alguns pontos históricos ajudam a entender essa premissa: (a) a interferência governamental ao longo de décadas, estimulando e, em muitos casos, bancando, ou seja, sendo ele mesmo o financiador e o executor de algumas frentes de desenvolvimento; (b) o movimento de desestatização e privatização ocorrido na década de 1990; e (c) a presença marcante do Estado brasileiro, agora de maneira indireta como acionista/proprietário.

Como exemplo, pode-se apontar o fato de que em 2009 o então Presidente da República Luiz Inácio não aprovava a estratégia da Vale S/A, privatizada desde 1997, pois a empresa exportava apenas commodities e não beneficiava o minério extraído, fato que, segundo o presidente, geraria mais empregos e desenvolvimento no país. Essas declarações ecoaram na Vale S/A por meio das empresas em que o governo detém participação direta ou indireta, quais sejam, a BNDESPar e a Litel, esta última tendo como acionistas fundos de previdência de estatais, a saber: Previ, Funcef e Petros. Tal atitude resultou em um investimento da ordem de $\mathrm{R} \$ 20$ bilhões e contemplava a instalação de duas plantas siderúrgicas, uma no Pará e outra no Ceará (Lazzarini, 2011).

As conexões políticas se dão por meio da ligação de empresas com o governo. Essa relação visa obter benesses mútuas, ou seja, tanto para empresa quanto para as pessoas envolvidas ou mesmo para o partido que esteja no poder. Nesse sentido, discute-se a existência de uma relação política entre os controladores, executivos ou membros do board e os governos ou os agentes políticos em geral. São inúmeras formas de se verificar a existência de Conexões Políticas, a saber: (a) quando no board da empresa ou mesmo na alta administração tem-se a presença de político, ex-político ou membro do governo; (b) pela doação às campanhas políticas, por parte da empresa ou das pessoas que fazem a alta administração da empresa ou o board dela; ou (c) pela participação do acionista governo nas empresas, quer de forma direta ou indireta (Camilo, 2011).

As conexões políticas podem se constituir como um fator limitador ou mesmo como uma variável que influencie a métrica do $\nabla$ do risco e poluir a carteira que disponha de um ou mais ativos conectados. A teoria moderna do portfólio versa que os investidores buscarão diversificar o risco em seus investimentos. Essa atitude acontece em decorrência do aspecto racional que eles assumem e de como o ativo deve ser precificado e relaciona-se com o retorno esperado daquele investimento (Carmona, 2009).

O processo de seleção de uma carteira de investimento divide-se em duas etapas: (a) uma inicial, voltada à observação e experiência do investidor; e (b) outra voltada apenas para o que os analistas acreditam sobre as expectativas futuras de retornos dos ativos. Markowitz (1952) centra suas análises na segunda opção e parte do pressuposto de que o investidor fez ou deveria fazer suas análises em função da maximização dos retornos esperados. Toda essa dinâmica entre retorno esperado e variância dos retornos ilustra as relações entre crenças e a escolha do portfólio.

A combinação perfeita entre os aspectos comportamentais que influenciam os analistas e o retorno das ações visando a construção de um portfólio foi desenvolvida a partir da teoria portfólio comportamental (behavioral portfolio theory (BPT)) de Shefrin e Statman (2000). Essa teoria se alicerça nos estudos da SP/A theory de Lopes (1987) e da prospect theory de Kahneman e Tversky (1979), sendo que as duas 
optam por analisar as escolhas sob incerteza. A prospect theory busca respaldo na literatura abordando o quebra-cabeça de Friedman e Savage (1948) e a BPT na observação de que as pessoas que compram apólices de seguros ao mesmo tempo também compram bilhetes de loteria (Shefrin \& Statman, 2000).

Diante desses fatos, chega-se à seguinte questão-problema: estariam os analistas propensos a manterem, na sua carteira de investimentos, empresas que têm conexões políticas explícitas?

Esse trabalho é motivado em primeiro lugar para suprir uma lacuna investigativa no Brasil, pois com o surgimento dessa nova linha de pesquisa que visa investigar as relações do governo com empresas sob a premissa das Conexões Políticas têm um flanco aberto para novas iniciativas e principalmente vêm despertando a atenção de pesquisadores internacionais para o caso brasileiro. Segundo, uma inquietação cidadã com o que vemos diariamente no noticiário e nós, como pesquisadores, devemos também nos voltar à investigação de problemas e questões nacionais.

O presente estudo objetiva analisar quão suscetíveis os analistas são a manterem, em sua carteira de investimentos, empresas que têm conexões políticas explicitas. A literatura aponta que tais conexões podem acontecer por intermédio da participação de membros do board e do conselho administrativo das empresas, por sua estrutura de propriedade ou pela doação a campanhas políticas. Visando atingir o objetivo, executou-se uma pesquisa experimental e analisaram-se os dados por meio de uma regressão logística, com testes de Hosmer e Lemeshow e de Count $\mathrm{R}^{2}$ e, complementarmente, crosstabs de dados característicos dos respondentes.

Como hipótese de pesquisa, o presente estudo traçou a seguinte:

H: Os analistas, com base na percepção de sua classificação política e na opção inicial de incluírem uma empresa no seu portfólio, são suscetíveis às conexões políticas.

\section{REVISÃO DE LITERATURA 2.1 Conexões políticas e suas estratégias}

O Estado brasileiro se mantém como uma força capaz de mobilizar e promover o desenvolvimento de áreas específicas da economia, por ser difícil o investimento privado ou por questões estratégicas. Essa presença representa, em inúmeros casos, posições de destaque e, muitas vezes, o modelo de gestão utilizado reveste-se do viés ideológico que impregna as ações governamentais. Verifica-se que, durante a década de 1990, o país viveu momentos de estagnação e altas taxas inflacionárias, os quais resultaram na adesão ao movimento mundial que culminou com a privatização de diversas empresas governamentais e a redução de sua participação na economia. No entanto, sabe-se o quanto, em alguns casos, o governo apenas mudou a forma de participar, dotando de protagonismo outros atores, entre os quais se podem enumerar: (a) Banco Nacional de Desenvolvimento Econômico e Social (BNDES); (b) fundos de pensões das empresas estatais; e (c) empresas de economia mista.

De outro lado, Brey e Camilo (2012, p. 3) afirmam que:

Outra forma de estratégia política corporativa é a interferência política na concorrência, ou seja, a influência na proposição, criação de regras e leis que dificultem a exploração de determinados setores, ou a pressão por estabelecimento de barreiras de entrada, como no caso de empresas estrangeiras ou novas competidoras no mercado doméstico. 
Algumas organizações que são conectadas ou dispõem de diretores, conselheiros e proprietários conectados, exercem essa influência e isso pode até agregar valor às firmas, ou seja, esse tipo de estratégia política remete à interferência do Estado e seus parceiros na economia como um todo.

No que tange à influência, deve-se ter em mente que, em alguns casos, apenas houve uma mudança da forma de participação do Estado na economia e, mesmo com todo o movimento de reestruturação ocorrido na década de 1990, alguns atores apresentam maior centralidade na economia nacional, influenciando-a, assim, como um todo. Tais atores podem exercer opções, colocar à venda posições acionárias e obter até privilégios em função das informações privilegiadas e das conexões políticas de seus gestores ou proprietários (Lazzarini, 2011).

O movimento de entrada de capital internacional, em alguns casos, revela anomalias e restrições, a exemplo da Telefônica e do Santander, que ficaram restritos e isolados em alguns setores, sem apresentar conexões com outros atores, e outras empresas internacionais ficaram reféns das complexas estruturas piramidais montadas para manter o controle em certas firmas. Tais casos são encontrados em fenômenos semelhantes na Ásia e na Hungria (Lazzarini, 2011).

Diversos autores se debruçam sobre a temática do tipo da influência para o valor das firmas, a partir de suas conexões políticas, e apontam que, em alguns casos, essas conexões resultam em atribuição de valor para a firma (Wu, 2011; Dinç, 2005; Camilo, 2011).

Em contrapartida aos estudos que afirmam existir relação positiva para as empresas conectadas, outros apresentam como fatores minimizadores dessa relação benéfica os custos da manutenção de tais conexões, a exemplo das evidências encontradas em países asiáticos (Brey \& Camilo, 2012; Boubakri, Cosset \& Saffar, 2008).

O governo, por ser o acionista majoritário nessas empresas, interfere para que as suas operações sejam alinhadas com as metas sociais e políticas de sua gestão. Tais ações visam o atingimento dos objetivos macros do governo por meio da nomeação de gestores com ligações políticas, como, por exemplo, o bem-estar social em detrimento da maximização do valor da companhia (Wu, Wu e Rui, 2012).

As conexões políticas vêm sendo objeto de estudos por vários autores: (a) sua influência na reestruturação de ativos de grupos econômicos brasileiros (Costa, 2012); (b) sua relação com desempenho, por meio da governança e dependência de recurso (Camilo, 2011); (c) estrutura de propriedade e dependência de recursos (Brey et al., 2011); (d) propriedade e empresas conectadas em Singapura (Ang \&Ding, 2006); (e) as conexões políticas e as firmas privatizadas recentemente na China (BOUBAKRI; Cosset \& Saffar, 2008); (f) controle do governo sobre as firmas privatizadas nos países da Organisation for Economic Co-operation and Development (OECD) (Bortolotti \& Faccio, 2009); (g) o acesso a financiamentos e doações para financiar campanhas políticas no Brasil (Claessens, Feijen e Laeven, 2008); (h) influência do governo nos bancos de sua propriedade e em países que estão em mercados emergentes (Dinç, 2005); (i) influência da propriedade, mesmo que minoritária, do governo, no valor da firma, na Tailândia (Wu, 2011); (j) propriedade e o valor da empresa, evidências na China (Wu, Wu e Rui, 2012); (I) estrutura de propriedade e desempenho financeiro, de mercado e alavancagem de empresas não financeiras listadas na Bovespa (Brey et al., 2011).

Por meio de vários estudos, chega-se a um cenário onde são expostas as conexões políticas; dessa forma, pode-se classificá-las em explicitas e implícitas: 
Quadro 1: Tipos de conexões políticas

\begin{tabular}{|l|l|}
\hline \multicolumn{1}{|c|}{ EXPLÍCITAS } & \multicolumn{1}{c|}{ IMPLÍCITAS } \\
\hline $\begin{array}{l}\text { Estrutura de Propriedade: Governo e suas organizações } \\
\text { como acionistas da empresa; }\end{array}$ & $\begin{array}{l}\text { Estrutura de Propriedade: Participação em empresas } \\
\text { através de estrutura piramidal, ou seja, o governo é sócio } \\
\text { de uma empresa e essa é proprietária/sócia a da outra; }\end{array}$ \\
\hline $\begin{array}{l}\text { Board e Conselhos: Presença de político, ex-político, } \\
\text { filiados de maneira em geral à partidos políticos ou } \\
\text { altos funcionários no board, conselhos ou diretoria; }\end{array}$ & $\begin{array}{l}\text { Board e Conselhos: Pessoas que são ligadas, no entan- } \\
\text { to, não dispõe de filiação partidária ou de histórico de } \\
\text { ligano com governo; }\end{array}$ \\
\hline \begin{tabular}{l} 
ou seus sócios para campanhas políticas; \\
\hline
\end{tabular} & $\begin{array}{l}\text { Financiamento de Campanha: Doações de membros dos } \\
\text { Board/Conselho de empresas para campanhas políticas; }\end{array}$ \\
\hline
\end{tabular}

Fonte: Elaboração própria a partir de Dinç (2005); Ang e Ding, (2006); Camilo, (2011); Wu; Wu; Rui, (2012)

\subsection{Teoria do portfólio e teoria portfólio comportamental}

Na teoria moderna do portfólio, verifica-se a necessidade dos investidores em buscarem a diversificação do risco em seus investimentos. Essa atitude acontece em decorrência do aspecto racional que eles assumem e como o ativo deve ser precificado e se relaciona com o retorno esperado daquele investimento. $O$ investidor almeja aproximar-se do risco em detrimento da incerteza, uma vez que ele será ou não propenso ao risco a partir de seu perfil. Para administrar o risco, existem alguns elementos: (a) hedging; (b) seguro; e (c) diversificação (Carmona, 2009).

Segundo Markowitz (1952), a seleção de uma carteira de investimento é feita seguindo um procedimento dividido em duas etapas principais: na primeira, o investidor analisará as empresas/ativos que irão compor a carteira de investimentos a partir da observação e de sua experiência; na segunda, ele buscará avaliar as expectativas futuras de retorno desses ativos pré-escolhidos. $\mathrm{O}$ autor desenvolve seu trabalho focado apenas na segunda etapa, uma vez que pressupõe que o investidor fez ou deveria ter feito tais análises que visam promover a maximização dos retornos esperados. As regras das relações entre crenças e escolha de portfólio de acordo com o retorno esperado e a variância dos retornos são ilustradas geometricamente no modelo proposto pelo autor (Markowitz, 1952).

Nos seus estudos, Shefrin e Statman (2000) compararam a fronteira eficiente da BPT com a da média-variância de Markowitz (1952), e encontraram que elas não coincidem, ou seja, as carteiras na fronteira eficiente da BPT geralmente não estão na fronteira eficiente da média-variância. O que permeia a decisão de cada um dos grupos é bem diferente: enquanto os investidores de média-variância escolhem suas carteiras considerando a média e variância. Os de BPT utilizam como pilares basilares de sua escolha a riqueza esperada, o desejo de segurança e potencial, os níveis de aspiração e as probabilidades de alcançarem os níveis de aspiração. Elas ainda diferem dos que optam pelo Capital Asset Pricing Model (CAPM), metaforicamente é o contraste das obrigações do seguro e da aquisição do bilhete da loteria (Shefrin \& Statman, 2000).

O BPT possui duas versões: (a) conta mental única (BPTSA); e (b) conta mental múltipla (BPTMA). Assim como os investidores de média-variância, os que integram suas carteiras em uma única conta mental consideram a covariância. Em contraste a essa premissa, os investidores da conta mental múltipla segregam suas carteiras em diversas contas e ignoram a covariância entre elas. Por exemplo, para os investidores BPTMA, é possível colocar as ações de empresas estrangeiras em uma conta mental e ações 
nacionais em outra. Eles podem considerar ações estrangeiras altamente arriscadas porque ignoram o efeito que a covariância entre ações de empresas estrangeiras e nacionais exerce sobre o risco da carteira, quando analisada como uma única conta integrada (Shefrin \& Statman, 2000).

A teoria da média variância (MVT) proposta por Markowitz (1952) assume que cada investidor tem a função de utilidade de consumo que depende do retorno esperado de sua carteira global e seu desvio-padrão. Suas análises são sob o aspecto da fronteira eficiente de média-variância e, entre as carteiras eficientes, cada um escolhe para consumir aquela que maximiza sua utilidade, combinando retornos esperados e riscos nas proporções ideais. Eles assumem as subcarteiras ou subcontas mentais como forma de segregar os objetivos de cada um dos ativos que escolhem para compor o portfólio (Das et al., 2010).

\section{PROCEDIMENTOS METODÓLOGICOS 3.1 Descrição Geral}

A presente pesquisa estruturou-se pelo método indutivo, como estratégia utilizou a abordagem quase-experimental, uma vez que o mesmo grupo respondeu a todas as etapas da pesquisa e, no decorrer desta, eles recebiam novas informações e eram questionados sobre a manutenção de sua decisão. Foram utilizadas as plataformas online do Google Docs ${ }^{\oplus}$, para hospedagem do questionário, e a do YouTube ${ }^{\oplus}$, para o vídeo. Os respondentes de todo o país foram convidados a participar por meio de convites nas redes sociais, como Facebook ${ }^{\circledR}$ e Twitter ${ }^{\circledR}$, como também em blogs especializados e correio eletrônico direcionado a professores, estudantes e outros profissionais, das áreas de ciências contábeis, administração, economia e afins, com graduação e pós-graduação.

Na busca por minimizar vieses, fizeram-se as seguintes opções: (a) nivelar os participantes da pesquisa promovendo-se sua contextualização por meio de um pequeno texto sobre o papel do analista de investimento, e nas questões específicas apresentou a empresa estudada e como seriam as conexões; (b) não foi divulgado o tema da pesquisa; e (c) na construção do vídeo, intercalaram-se imagens com legendas dos mais variados políticos de diversos partidos.

A escolha desse tipo de conexão política explícita, ou seja, por meio do financiamento de campanhas, se deu, uma vez que, é uma das formas mais explícitas que o indivíduo está ligado a um grupo político, bem como, integra um debate atual da reforma política no país. No que tange ao meio as evidências empíricas, estudos relacionados a esse tipo, já vem sendo feitos por diversos pesquisadores, como é o caso de Claessens; Feijen e Laeven, (2008), que estudaram as campanhas no país de 1998 e 2002.

O participante foi convidado a responder a primeira parte do questionário, onde se buscou apreender do inquirido o posicionamento político e a caracterização de identidade amostral ao qual estava ligado, já sendo apresentado a uma questão central do estudo, onde não existe o "gatilho" da conexão. Depois foram apresentadas duas situações seguidas, vistas no referencial teórico (Quadro 2): 
Quadro 2: Situações de conexões segundo a literatura

\begin{tabular}{|c|l|c|}
\hline Ord. & \multicolumn{1}{|c|}{ Descrição da situação } & Base teórica \\
\hline 1 & $\begin{array}{l}\text { Relacionando a empresa Beta ao financiamento de campanhas eleitorais, desde } \\
\text { a década de 1990, e mais fortemente na campanha de } 2010 \text { para Presidência da } \\
\text { República, onde financiara o partido vencedor e conseguiria contratos novos, que } \\
\text { geraram um lucro acima do esperado após o início do governo. Diante desses fatos, } \\
\text { analistas políticos imaginam que provavelmente a empresa Beta será convocada } \\
\text { a, no próximo ano (2014), financiar a campanha presidencial do partido. }\end{array}$ & $\begin{array}{c}\text { Laeven } \\
\text { (2008) }\end{array}$ \\
\hline 2 & $\begin{array}{l}\text { A empresa Beta teve uma importante parcela de seu capital adquirida por dois } \\
\text { fundos de pensões de empresas estatais (propriedade). A consequência dessa } \\
\text { aquisição é que, como na assembleia que acontecerá no próximo mês, esses dois } \\
\text { fundos de pensões estatais irão indicar 50\% do Conselho de Administração e a } \\
\text { Presidência da empresa. }\end{array}$ & Ang e \\
Ding \\
(2006)
\end{tabular}

Fonte: Elaboração própria, a partir de dados da pesquisa (2013).

O vídeo utilizado no estudo buscou mostrar a associação da imagem de empresários, especialmente aqueles de sucesso no país, e políticos, presidentes, governadores e outros. Nesse sentido, ele apresentava uma tela de fundo preto com o nome do político e do empresário, depois a foto e um rodapé, repetindo o nome dos personagens. Dessa forma, imagina-se que essa vinculação produziria um afloramento da percepção sobre a conexão política.

A população foi de 408 (quatrocentos e oito) observações, porém, ao analisar a variável dependente, relacionada à opção de manter a empresa no portfólio após a descoberta de que ela doa para campanhas eleitorais, verificou-se que 100 (cem) respondentes nem concordam nem discordam com ela, sendo, assim, excluídos na amostra final, restando um total de 308 (trezentos e oito) questionários. Esta amostra é considerada não probabilística, pois se deu em função da sensibilização para os respondentes participarem da pesquisa, ou seja, por acessibilidade a eles.

\subsection{Modelo Estatístico}

A presente pesquisa utilizou-se do modelo Logit ou de regressão logística, visto que a variável dependente é binária, ou seja, manter ou não a empresa no portfólio. A regressão logística assume algumas características, dentre as quais se elenca a capacidade de estimação de probabilidade de ocorrer eventos diante de variáveis agrupadas e explanatórias (Corrar, Paulo e Dias Filho, 2009). A função de distribuição logística do modelo Logit descrita por Gujatari (2006, p. 480), apresenta a base do modelo (Equação 1):

$$
P_{i}=E\left(Y_{i}=1 \mid X_{i}\right)=\frac{1}{1+e^{-\left(\beta_{1}+\beta_{2} X_{i}\right)}}
$$


Como a regressão logística centra seus esforços na descoberta da probabilidade da ocorrência de determinado fato, ela almeja explicar ou predizer os valores de uma variável em função de valores conhecidos de outras (Corrar, Paulo E Dias Filho, 2009).

Quadro3: Descrição das variáveis do modelo

\begin{tabular}{|c|c|c|c|}
\hline Tipo & Descrição & Caracterização & Sigla \\
\hline $\begin{array}{l}\text { Variável indepen- } \\
\text { dente }\end{array}$ & $\begin{array}{l}\text { Mantenho no } \\
\text { meu portfólio a } \\
\text { empresa }\end{array}$ & $\begin{array}{l}\text { Categorizada por uma questão que figurava no } 2^{\circ} \\
\text { bloco, após o vídeo, construída a partir da mensura- } \\
\text { ção percepção pela escala de Likert e posteriormente } \\
\text { tratada com eliminação da posição } 3 \text { (nem concordo } \\
\text { nem discordo) e junção das posições } 1 \text { e 2, como, } \\
\text { também, } 4 \text { e } 5 \text {, que representam, respectivamente, } \\
\text { discordo fortemente, discordo, concordo e concordo } \\
\text { fortemente. }\end{array}$ & MAN \\
\hline \multirow{6}{*}{$\begin{array}{l}\text { Variável indepen- } \\
\text { dente }\end{array}$} & $\begin{array}{l}\text { Classificação po- } \\
\text { lítica }\end{array}$ & $\begin{array}{l}\text { Categorizava o posicionamento político, variando } \\
\text { em esquerda, centro-esquerda, centro, centro-direita } \\
\text { e direita. }\end{array}$ & CLAS \\
\hline & Filiação partidária & $\begin{array}{l}\text { Buscava inferir se o respondente teria ou não a filiação } \\
\text { a alguma agremiação partidária formal no país. }\end{array}$ & FIL \\
\hline & $\begin{array}{l}\text { Ajuda do Estado } \\
\text { às empresas em } \\
\text { dificuldade }\end{array}$ & $\begin{array}{l}\text { Norteava a figura dos que se diziam de esquerda, } \\
\text { ou seja, a favor do apoio do Estado às empresas em } \\
\text { dificuldade. }\end{array}$ & AJU \\
\hline & $\begin{array}{l}\text { O Estado como } \\
\text { motor da econo- } \\
\text { mia }\end{array}$ & $\begin{array}{l}\text { Representava a confirmação de que realmente o } \\
\text { respondente é de esquerda. }\end{array}$ & MOT \\
\hline & $\begin{array}{l}\text { Ter indicado a } \\
\text { empresa para o } \\
\text { portfólio }\end{array}$ & $\begin{array}{l}\text { Correspondia ao que preceitua a teoria econômica, } \\
\text { onde, pelo fato de o ativo já pertencer ao portfólio, } \\
\text { dificilmente o respondente o retirará. }\end{array}$ & IND \\
\hline & Profissão & $\begin{array}{l}\text { Intuitivamente desejou-se a segregação e, assim, } \\
\text { possivelmente haveria uma mudança de acordo com } \\
\text { o perfil profissional. }\end{array}$ & PROF \\
\hline Variável dummy & $\begin{array}{l}\text { Ter assistido ao ví- } \\
\text { deo com imagens } \\
\text { de conexões po- } \\
\text { líticas }\end{array}$ & $\begin{array}{l}\text { Buscava inferir a influência da imagem para os res- } \\
\text { pondentes. }\end{array}$ & $\begin{array}{l}\text { DUM } \\
\text { ASS }\end{array}$ \\
\hline
\end{tabular}


A inclusão dos questionamentos "ajuda do Estado às empresas em dificuldade" e "o Estado como motor da economia" justifica-se, pois se está lidando com respondentes vinculados à universidade e historicamente têm ligações fortes com os movimentos sociais de esquerda, fato que num primeiro momento poderia se confirmar pela auto declaração feita no quesito da "classificação política"

O modelo Logit utilizado na pesquisa é descrito abaixo, na forma de sua Equação 2:

$$
P_{i}=\frac{1}{1+e^{-\left(\left(-\left(\mathrm{C}(1)^{*} \mathrm{CLAS}+\mathrm{C}(2) * \mathrm{FIL}+\mathrm{C}(3)^{*} \mathrm{AJU}+\mathrm{C}(4) * \mathrm{MOT}+\mathrm{C}(5)^{*} \mathrm{IND}+\mathrm{C}(6)^{*} \mathrm{PROF}+\mathrm{C}(7) * \mathrm{DUM} \_\mathrm{ASS}+\mathrm{C}(8)\right)\right)\right.}}
$$

A regressão logística estima seus parâmetros não por mínimos quadrados, como visto na regressão simples ou múltipla. Ela se utiliza da máxima verossimilhança, por não ser um modelo linear. O modelo Logit evidencia a probabilidade de um evento ocorrer, sendo apresentado pelo logaritmo da razão da chance. Dessa forma, mede-se a variação no Logit estimado em relação à probabilidade de variação da variável independente (Gujarati, 2006).

Como forma de avaliar a significância estatística do modelo estimado, utilizaram-se dois testes: (a) estatística Z; e (b) LR statistic (teste da razão da verossimilhança). Por meio da estatística Z, verifica-se a significância de cada parâmetro isolado; já a LR statistic analisa o modelo completo.

Nas regressões lineares, o nível de ajustamento do modelo aos dados é avaliado por meio do $R^{2}$; no entanto, para o modelo Logit, não existe um coeficiente de determinação - para esta função, o modelo apresenta indicadores que são semelhantes e pela literatura se conhece por "pseudos $\mathrm{R}^{2 \text { " (Corrar, Paulo }}$ e Dias Filho, 2009).

Com vistas à complementação dessa avaliação para o caso em tela, opta-se por analisar tal ajustamento por meio dos testes de Hosmer e Lemeshow e de Count $\mathrm{R}^{2}$. O teste de Hosmer e Lemeshow baseia-se na categorização do número de observações, objetivando promover a comparação da frequência que era prevista e o que foi realmente observado, tal categorização é feita em 10 (dez) diferente classes, com o propósito de analisar se existem diferenças significativas entre o que era previsto pelo modelo e o que aconteceu de fato (Corrar, Paulo e Dias Filho, 2009).

Outro teste utilizado foi o de Count $\mathrm{R}^{2}$, que objetiva verificar se o modelo obteve sucesso em prever os resultados binários, seu output aponta que, se a probabilidade prevista de um elemento for maior que 0,5 (zero vírgula cinco), classifica-o como 1 (um), e se for menor que 0 (zero), posteriormente se calcula um quociente, no qual relacionam-se as previsões corretas e o número total das observações. Acessoriamente poder-se-ia minimizar o número de classificações incorretas do modelo e apontar as variáveis que auxiliam nesse processo. A fórmula do teste Count $R^{2}$ é apresentada na Equação 3, conforme Gujatari (2006, p. 488):

$$
\text { Count } \mathrm{R}^{2}=\frac{\text { Número de previsões corretas }}{\text { Número total de observações }}
$$

A regressão logística e os testes de Hosmer e Lemeshow e de Count $R^{2}$ foram estimados com o auxílio do software estatístico Eviews $3.0^{\oplus}$. Já as crosstabs da estatística descritiva foram elaboradas a partir do software estatístico SPSS ${ }^{\circledR}$ versão 15.0 para Windows. 


\section{APRESENTAÇÃO E ANÁLISE DOS DADOS}

A apresentação e análise dos dados foram divididas em duas seções, uma compreende apenas as tabelas e crosstabs de frequência, e a outra a análise do modelo desenvolvido estatisticamente.

\subsection{Perfil dos entrevistados}

A Tabela 1 apresenta o perfil dos respondentes quanto ao tipo (aluno, professor ou outro profissional) e sua área de atuação. Vê-se uma predominância da área contábil, fato que se deve à ligação da área e programa contatados dos pesquisadores. Adicionalmente, foi solicitado aos respondentes que fossem professores, mas no momento estivessem cursando pós-graduação, que optassem por aluno.

\begin{tabular}{|c|c|c|c|c|c|c|}
\hline \multirow{2}{*}{$\begin{array}{c}\text { Tipo do } \\
\text { respondente }\end{array}$} & \multicolumn{5}{c|}{ Área de atuação } & \multirow{2}{*}{ Total } \\
\cline { 2 - 7 } & Administração & C. Contabéis & Economia & Áreas afins & Outro & \\
\hline Aluno & 37 & 104 & 1 & 1 & 14 & 157 \\
\hline Professor & 26 & 61 & 5 & 3 & 4 & 99 \\
\hline Outro profissional & 8 & 29 & 2 & 5 & 8 & 52 \\
\hline Total & 71 & 194 & 8 & 9 & 26 & 308 \\
\hline
\end{tabular}

Fonte: Elaboração própria, a partir de dados da pesquisa (2013).

Outro ponto basilar do perfil relacionava-se com a percepção de como os inquiridos se classificavam politicamente. Para referendar essa medida, questionou-se, ainda, se eram filiados a algum partido político. Como se verifica na Tabela 2, o maior público é apolítico e não filiado.

Tabela 2: Classificação política do respondente e se é ou não filiado a partido político

\begin{tabular}{|c|c|c|c|}
\hline \multirow{2}{*}{ Classificação política } & \multicolumn{2}{|c|}{ Filiado } & \multirow{2}{*}{ Total } \\
\cline { 2 - 4 } & Sim & Não & \\
\hline Esquerda & 6 & 38 & 44 \\
\hline Centro-esquerda & 5 & 49 & 54 \\
\hline Centro & 5 & 45 & 30 \\
\hline Centro-direita & 3 & 27 & 30 \\
\hline Direita & 3 & 42 & 45 \\
\hline Apolítico & 4 & 81 & 85 \\
\hline Total & 26 & 282 & 308 \\
\hline
\end{tabular}

Fonte: Elaboração própria, a partir de dados da pesquisa (2013).

Verificou-se que, em decorrência da postura "politicamente correta" evidenciada por uma divisão bem equitativa e uma grande opção pelo apolítico nas respostas da Tabela 2, alguns dos respondentes poderiam responder ao questionário de forma aviesada e não declarar a sua real preferência política. Buscando minimizar tal efeito, optou-se por questioná-los sobre o que achavam das posturas do Estado relacionado com: (a) o auxílio às empresas em dificuldades financeiras; e (b) ser o maior motor da 
economia. As respostas obtidas no item confirmaram a postura apolítica do grupo de respondentes e que fora verificada no quesito anterior.

Tabela 3: Classificação política do respondente e se é ou não filiado a partido político

\begin{tabular}{|c|l|l|l|l|l|l|}
\hline \multirow{2}{*}{\begin{tabular}{c} 
O maior motor da $\begin{array}{c}\text { O Estado deve ajudar empresas em dificuldades financeiras } \\
\text { economia é o Estado }\end{array}$ \\
\cline { 3 - 8 }
\end{tabular}} & $\begin{array}{c}\text { Discordo } \\
\text { fortemente }\end{array}$ & Discordo & $\begin{array}{c}\text { Nem discordo / } \\
\text { nem concordo }\end{array}$ & Concordo & $\begin{array}{c}\text { Concordo } \\
\text { fortemente }\end{array}$ & Total \\
\hline Discordo fortemente & 18 & 4 & 5 & - & 4 & 31 \\
\hline Discordo & 12 & 26 & 9 & 12 & 3 & 62 \\
\hline Nem disc/nem conc. & 11 & 30 & 38 & 19 & 6 & 104 \\
\hline Concordo & 9 & 27 & 24 & 12 & 7 & 79 \\
\hline Concordo fortemente & 5 & 6 & 7 & 4 & 10 & 32 \\
\hline Total & 55 & 93 & 83 & 47 & 30 & 308 \\
\hline
\end{tabular}

Fonte: Elaboração própria, a partir de dados da pesquisa (2013).

\subsection{Dados estatísticos do modelo utilizado}

Nesta seção apresentam-se os resultados da regressão logística, estimada no software Eviews ${ }^{\oplus}$, com o output abaixo:

Tabela 4: Output do modelo estatístico de rearessão loaística Dependent Variable: Mantenho no meu portfólio a empresa (MAN) Method: ML - Binary Logit Sample: 1308 Included observations: 308

Convergence achieved after 4 iterations Covariance matrix computed using second derivatives

\begin{tabular}{|l|r|r|r|r|}
\hline Variable & Coefficient & Std. Error & z-Statistic & Prob. \\
\hline Ajuda do estado às empresas (AJU) & -0.106323 & 0.111706 & -0.951815 & 0.3412 \\
Classificação política (CLAS) & -0.128156 & 0.070959 & -1.806047 & 0.0709 \\
Dummy ter assistido ao vídeo (DUM_ASS) & -0.128306 & 0.448921 & -0.285810 & 0.7750 \\
Filiação partidária (FIL) & -0.763779 & 0.442712 & -1.725229 & 0.0845 \\
Indicar a empresa sem conhec. da conexão (IND) & 0.645479 & 0.139047 & 4.642158 & 0.0000 \\
Estado como motor da economia (MOT) & 0.018724 & 0.119572 & 0.156595 & 0.8756 \\
Respondente/profissão (PROF) & -0.161706 & 0.173950 & -0.929613 & 0.3526 \\
Constante (C) & -0.390197 & 1.172679 & -0.332740 & 0.7393 \\
& & & & \\
\hline Mean dependent var & 0.340909 & S.D. dependent var & 0.474786 \\
S.E. of regression & 0.452129 & Akaike info criterion & 1.229423 \\
Sum squared resid & 61.32610 & Schwarz criterion & 1.326309 \\
Log likelihood & -181.3311 & Hannan-Quinn criter. & 1.268162 \\
Restr. log likelihood & -197.6241 & Avg. log likelihood & -0.588737 \\
LR statistic (7 df) & 32.58587 & McFadden R-squared & 0.082444 \\
\hline Probability(LR stat) & $3.16 \mathrm{E}-05$ & & \\
\hline
\end{tabular}




\begin{tabular}{|l|r|r|}
\hline Obs with $\operatorname{Dep}=0$ & 203 & \\
Obs with $\mathrm{Dep}=1$ & 105 & Total obs 308 \\
\hline
\end{tabular}

Fonte: Elaboração própria, a partir de dados da pesquisa (2013).

Apreende-se do teste que o nível de significância do modelo é de 3.16E-05, ou seja, 0,0000316, apresentando-se, com isso, que pelo menos uma variável não é zero - daí, ao analisar-se a 10\%, verifica-se que:

Tabela 5: Decisão quanto as variáveis ao nível de significância de 10\%

\begin{tabular}{|c|l|l|c|}
\hline Ord. & \multicolumn{1}{|c|}{ Variáveis } & \multicolumn{1}{c|}{ Prob. } & Decisão \\
\hline 1 & Classificação política (CLAS) & 0.0709 & Rejeito H0 \\
\hline 2 & Filiação partidária (FIL) & 0.0845 & Rejeito H0 \\
\hline 3 & Indicar a empresa sem conhecimento da conexão (IND) & 0.0000 & Rejeito H0 \\
\hline 4 & Ajuda do estado às empresas (AJU) & 0.3412 & Não rejeito H0 \\
\hline 5 & Respondente/profissão (PROF) & 0.3526 & Não rejeito H0 \\
\hline 6 & Estado como motor da economia (MOT) & 0.8756 & Não rejeito H0 \\
\hline 7 & Dummy ter assistido ao vídeo (DUM_ASS) & 0.7750 & Não rejeito H0 \\
\hline
\end{tabular}

Fonte: Elaboração própria, a partir de dados da pesquisa (2013).

Com os dados evidenciados pela Tabela 5, verifica-se que as variáveis: (a) classificação política (CLAS); (b) filiação partidária (FIL); e (c) indicar a empresa sem conhecimento da conexão (IND) são significativas a 10\% para o modelo, enquanto que as variáveis: (d) ajuda do Estado às empresas (AJU); (e) respondente/profissão (PROF); (f) Estado como motor da economia (MOT); e (g) dummy ter assistido ao vídeo (DUM_ASS), não foram significativas e apontaram para rejeição de H0.

Foi realizado ainda o teste de Count $R^{2}$ e com base nos seus resultados pode-se afirmar que o modelo acertou $70,45 \%$ das previsões, errando apenas $29,55 \%$ delas, fato que referenda o poder explicativo do modelo Logit desenhado para a hipótese de pesquisa, conforme Tabela 6.

\begin{tabular}{|c|c|c|c|c|c|c|}
\hline & & & & & Tabela 6: O & te de Count $R^{2}$ \\
\hline Dependent Variab & :Mantenh & no meup & tfólio a el & presa (MAI & Meth & 3inary Logit \\
\hline Date: 06/25/13 Ti & e: $17: 34$ & & & & & mple: 1308 \\
\hline Included observat & ns: 308 & & & Predictior & Evaluation (st & toff $C=0.5$ ) \\
\hline & & nated Equ & & & Constant Prc & \\
\hline & Dep $=0$ & $\mathrm{Dep}=1$ & Total & $\operatorname{Dep}=0$ & $\operatorname{Dep}=1$ & Total \\
\hline$P($ Dep $=1)<=C$ & 187 & 75 & 262 & 203 & 105 & 308 \\
\hline$P(\operatorname{Dep}=1)>C$ & 16 & 30 & 46 & 0 & 0 & 0 \\
\hline Total & 203 & 105 & 308 & 203 & 105 & 308 \\
\hline Correct & 187 & 30 & 217 & 203 & 0 & 203 \\
\hline$\%$ Correct & 92.12 & 28.57 & 70.45 & 100.00 & 0.00 & 65.91 \\
\hline$\%$ Incorrect & 7.88 & 71.43 & 29.55 & 0.00 & 100.00 & 34.09 \\
\hline Total Gain* & -7.88 & 28.57 & 4.55 & & & \\
\hline Percent Gain** & NA & 28.57 & 13.33 & & & \\
\hline
\end{tabular}




\begin{tabular}{|c|c|c|c|c|c|c|}
\hline & \multicolumn{3}{|c|}{ Estimated Equation } & \multicolumn{3}{|c|}{ Constant Probability } \\
\hline & Dep $=0$ & Dep $=1$ & Total & Dep $=0$ & $\mathrm{Dep}=1$ & Total \\
\hline$E(\#$ of $D e p=0)$ & 141.21 & 61.79 & 203.00 & 133.80 & 69.20 & 203.00 \\
\hline$E(\#$ of $D e p=1)$ & 61.79 & 43.21 & 105.00 & 69.20 & 35.80 & 105.00 \\
\hline Total & 203.00 & 105.00 & 308.00 & 203.00 & 105.00 & 308.00 \\
\hline Correct & 141.21 & 43.21 & 184.43 & 133.80 & 35.80 & 169.59 \\
\hline$\%$ Correct & 69.56 & 41.16 & 59.88 & 65.91 & 34.09 & 55.06 \\
\hline$\%$ Incorrect & 30.44 & 58.84 & 40.12 & 34.09 & 65.91 & 44.94 \\
\hline Total Gain* & 3.65 & 7.07 & 4.82 & & & \\
\hline Percent Gain** & 10.72 & 10.72 & 10.72 & & & \\
\hline
\end{tabular}

Fonte: Elaboração própria, a partir de dados da pesquisa (2013).

O teste de Hosmer e Lemeshow possui uma hipótese nula que pressupõe a não existência de diferença entre os valores previstos e observados. Diante desse fato, a 8 graus de liberdade o modelo não rejeita $\mathrm{HO}$, pois seu resultado foi $0,05<0.1879$. Tal afirmação denota que o modelo desenvolvido é aderente aos dados, como se pode visualizar na Tabela 7:

Tabela 7: Output do teste Hosmer-Lemeshow

\begin{tabular}{|c|c|c|c|c|c|c|c|c|}
\hline \multicolumn{7}{|c|}{ Dependent Variable: Mantenho no meu por } & \multicolumn{2}{|c|}{ Method: ML - Binary Logit } \\
\hline \multicolumn{7}{|c|}{ Date: 06/25/13 Time: } & & Sample: 1308 \\
\hline \multicolumn{7}{|c|}{ Andrews and Hosmer-Lemeshow Goodness-of-Fit Tests } & \multicolumn{2}{|c|}{ Included observations: 308} \\
\hline \multicolumn{9}{|c|}{ Grouping based upon predicted risk (randomize ties) } \\
\hline & \multicolumn{2}{|c|}{ Quantile of Risk } & \multicolumn{2}{|c|}{$\mathrm{Dep}=0$} & \multicolumn{2}{|c|}{$\mathrm{Dep}=1$} & Total & $\mathrm{H}-\mathrm{L}$ \\
\hline & Low & High & Actual & Expect & Actual & Expect & Obs. & Value \\
\hline 1 & 0.0455 & 0.1442 & 24 & 27.0289 & 6 & 2.97107 & 30 & 3.42735 \\
\hline 2 & 0.1451 & 0.2028 & 26 & 25.6352 & 5 & 5.36478 & 31 & 0.02999 \\
\hline 3 & 0.2045 & 0.2570 & 25 & 23.9682 & 6 & 7.03178 & 31 & 0.19581 \\
\hline 4 & 0.2593 & 0.2975 & 24 & 22.3921 & 7 & 8.60786 & 31 & 0.41578 \\
\hline 5 & 0.2981 & 0.3289 & 25 & 21.3464 & 6 & 9.65364 & 31 & 2.00816 \\
\hline 6 & 0.3306 & 0.3750 & 17 & 19.4346 & 13 & 10.5654 & 30 & 0.86597 \\
\hline 7 & 0.3757 & 0.4268 & 19 & 18.6322 & 12 & 12.3678 & 31 & 0.01820 \\
\hline 8 & 0.4283 & 0.4614 & 20 & 17.2203 & 11 & 13.7797 & 31 & 1.00942 \\
\hline 9 & 0.4614 & 0.5534 & 16 & 15.4673 & 15 & 15.5327 & 31 & 0.03662 \\
\hline 10 & 0.5546 & 0.8146 & 7 & 11.8748 & 24 & 19.1252 & 31 & 3.24374 \\
\hline Total & & & 203 & 203.000 & 105 & 105.000 & 308 & 11.2510 \\
\hline \multicolumn{2}{|c|}{ H-L Statistic: } & 1.2510 & & \multicolumn{3}{|c|}{ Prob[Chi-Sq(8 df)]: } & & 0.1879 \\
\hline \multicolumn{4}{|c|}{ Andrews Statistic: 12.5662} & \multicolumn{3}{|c|}{ Prob[Chi-Sq(10 df)]: } & & 0.2489 \\
\hline
\end{tabular}




\section{CONCLUSÕES}

O presente estudo teve como norte, respectivamente, a questão-problema (estariam os analistas propensos a manterem empresas, na sua carteira de investimentos, que têm conexões políticas explicitas?) e a hipótese de pesquisa (os analistas, com base na percepção de sua classificação política e na opção inicial de incluir uma empresa no seu portfólio, são suscetíveis às conexões políticas).

Num primeiro momento, imaginava-se que alguns fatores eram preponderantes e influenciariam a escolha dos analistas, daí trabalhou-se no instrumento de pesquisa e incluíram-se as variáveis: (a) classificação política (CLAS); (b) filiação partidária (FIL); (c) indicar a empresa sem conhecimento da conexão (IND); (d) ajuda do Estado às empresas (AJU); (e) respondente/profissão (PROF); (f) Estado como motor da Economia (MOT); e (g) dummy ter assistido ao vídeo (DUM_ASS).

No entanto, o nível de significância utilizado a partir dos resultados da regressão logística apontou que apenas a classificação política (CLAS), a filiação partidária (FIL) e o fato de se ter indicado a empresa para participar do portfólio (IND), foram estatisticamente significativas. Com base na teoria da propriedade, corrobora com o fato de o respondente ter anteriormente indicado a empresa para compor sua carteira quando não havia informações que denotavam suas conexões políticas.

Chega-se, ainda, à conclusão de que a conexão política não é percebida pelas imagens de interações de políticos e empresários, mas pelas informações da mídia em geral, uma vez que o fato de ter assistido ao vídeo não influencia o modelo.

Para as próximas pesquisas, sugere-se buscar um público que seja do mercado, ou com um conhecimento prévio de finanças/mercado financeiro, bem como tentar avaliar adicionalmente as empresas por outros dados econômico-financeiros, e não apenas pelas informações diretas induzidas. 


\section{REFERÊNCIAS}

Ang, James S. \& Ding, David K. (2006). Government ownership and the performance of government-linked companies: the case of Singapore. Journal of Multinational Financial Management, Columbia, 16(1) 64-88.

Bortolotti, Bernardo \& Faccio, Mara. (2009). Government control of privatized firms. The Review of Financial Studies, Oxford, 22(8), 2907-2939.

Boubakri, Narjess, Cosset, Jean-Claude e Saffar, Walid. (2008). Political connections of newly privatized firms. Journal of Corporate Finance, Georgia, 14(5), 654-673.

Brey, Nathanael Kusch \& Camilo, Sílvio Parodi Oliveira. (2012). Conexões políticas em estruturas de propriedade: o governo como acionista. In: ENCONTRO DA ANPAD, 36., Rio de Janeiro. Anais... Rio de Janeiro: ANPAD.

Brey, Nathanael Kusch, Camilo, Sílvio Parodi Oliveira, Marcon, Rosilene e Alberton, Anete. (2011). A estrutura de propriedade das corporações: conexões políticas sob a perspectiva da dependência de recursos. Revista Ibero-americana de Estratégia - RIAE, São Paulo, 10(3), 126-146, set./dez.

Camilo, Silvio Parodi Oliveira. (2011). Conexões políticas e desempenho das empresas listadas na BM\&FBovespa: análise sob a ótica da governança e da dependência de recursos. 223 f. Tese (Doutorado em Administração e Turismo) - Univali, Biguaçu-SC, Brasil.

Carmona, Charles Ulises de Montreuil. (2009). Finanças corporativas e mercados. São Paulo: Atlas.

Claessens, Stijn, Feijen, Erik e Laeven, Luc. (2008). Political connections and preferential access to finance: the role of campaign contributions. Journal of Financial Economics, New York, 88(3), 554-580.

Corrar, Luiz J., Paulo, Edilson e Dias Filho, José Maria. (2009). Análise multivariada para os cursos de administração, ciências contábeis e economia. São Paulo: Atlas.

Costa, Maick William Oliveira. (2012). A influência da conexão política na reestruturação de ativos dos grupos econômicos no Brasil. 75 f. Dissertação (Mestrado em Administração de Empresas) - EAESP, FGV, São Paulo, SP, Brasil.

Cruz, Adriana I. G. da. et al. (2012). BNDES 60 anos: perspectivas setoriais, 1.

Das, Sanjiv, Markowitz, Harry, Scheid, Jonathan e Statman, Meir. (2010). Portfolio optimization with mental accounts. Journal of Financial and Quantitative Analysis, 45(2). 311-334.

Dinç, I. Serdar. (2005). Politicians and banks: political influences on government-owned banks in emerging markets. Journal of Financial Economics, New York, 77(2), 453-479. 
Gujarati, Damodar N. (2006). Econometria básica. 4. ed. Rio de Janeiro: Campos.

Lazzarini, Sérgio G. (2011). Capitalismo de laços: os donos do Brasil e suas conexões. 4. reimp. Rio de Janeiro: Elsevier.

Markowitz, Harry. (1952). Portfolio selection. The Journal of Finance, 7(1), 77-91.

Shefrin, Hersh \& Statman, Meir. (2000). Behavioral portfolio theory. Journal of Financial and Quantitative Analysis, 35(2), 127-151.

Wu, Hsueh-liang. (2011). Can minority state ownership influence firm value? Universal and contingency views of its governance effects. Journal of Business Research, Boston, 64(8), 839-845.

Wu, Wenfeng, Wu, Chongfeng e Rui, Oliver M. (2012). Ownership and the value of political connections: evidence from China. European Financial Management, 18(4), 695-729. 


\section{Apêndice A - Formulário do Questionário WEB}

Esta é uma pesquisa do doutorado.

OBSERVAÇÃO IMPORTANTE: A presente pesquisa utiliza apenas dados fictícios, os dados aqui apresentados não têm nenhuma relação com a realidade.

Classificação demográfica

O que você faz?

1. Eu sou *

Obs: Se você é professor e também aluno (Tipo: mestrando(a), doutorando(a), favor considerar a opção aluno)

Marcar apenas uma oval.

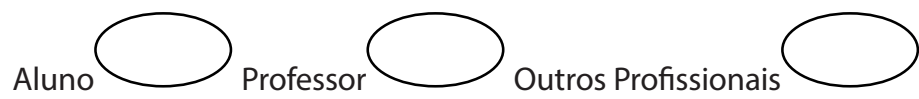

2. Na área de *

Marcar apenas uma oval.

Administração $\longrightarrow$ Ciências Contábeis $\longrightarrow$

Outras áreas ligada a negócios e afins (Ex.:Secretariado, Ciência da Informação e etc)

Outro:

3. Se sou aluno, sou de:

Marcar apenas uma oval.
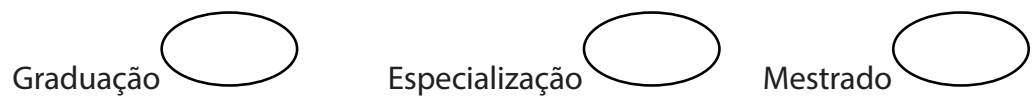

Doutorado

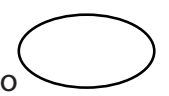

Classificação política

Como você se classifica politicamente.

4. Eu me percebo um ser político, sou de: *

Marcar apenas uma oval.

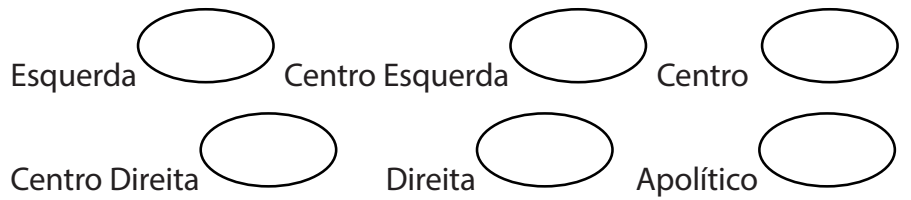


5. Você é filiado a partido político? *

Marcar apenas uma oval.

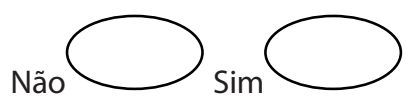

6. Se respondeu SIM na questão anterior, qual o partido que você é filiado?

7. O maior motor da economia é o Estado *

Marcar apenas uma oval. 1

Discordo fortemente

Concordo fortemente

8. O Estado deve ajudar empresas em dificuldades financeiras * Marcar apenas uma oval.

1

2

3

4

5

Discordo fortemente

Concordo fortemente

\section{Cenário 1}

Você é um(a) analista de mercado de uma corretora de ações e está analisando a empresa Beta, para compor seu portfólio de investimento.

O que faz um Analista de Investimentos no seu dia a dia?

O Analista de Investimento em Ações pela ótica fundamentalista (há também os analistas gráficos) precisa administrar um grande conjunto de informações, com o objetivo de transmitir aos clientes recomendações sobre as ações negociadas na Bolsa de Valores. Há analistas que se dedicam mais especificamente à análise macroeconômica, assim como há aqueles que analisam cada empresa de capital aberto, especificamente, percebendo se o momento é adequado para o investimento em suas ações. Para isso normalmente recorrem aos modelos amplamente conhecidos e utilizados no mundo inteiro, que podem ser resumidos em dois: modelo de fluxo de caixa descontado e modelo de avaliação relativa (ou de múltiplos).

(fonte: http://liliangallagher.wordpress.com/)

Para sua decisão, você deverá utilizar apenas os dados aqui fornecidos.

Dados da empresa Beta

A empresa Beta é uma das empresa sólida, que atua no mercado a 20 anos, fez a sua abertura de capital na década de 90 . A relação da empresa Beta com as demais empresas da sua carteira é muito baixa, com isso entendesse que, ao se ter uma empresa da carteira influenciada por algum movimento da economia, a empresa Beta irá sofrer uma interferência mínima neste processo. Ela atua num setor que sofre pouca interferência externa e seus produtos são bem aceitos no mercado nacional.

Diante deste fato, você, concorda ou discorda a afirmativa abaixo: 
9. Eu indicaria esta empresa Beta para compor a carteira de investimentos, já que ao Analisa-la ela cumpre os pressupostos para sua inclusão no portfólio. *

Marcar apenas uma oval.

1

2

3

4

5

Discordo fortemente

Concordo fortemente

Vídeo

Assista o vídeo, antes de dar continuidade a pesquisa

http://www.youtube.com/watch?v=p7fz8Zqnx9l

10. Você assistiu o vídeo ? *

Marcar apenas uma oval.

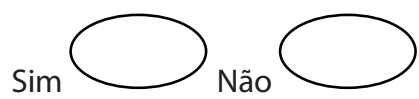

Relembrando os dados da empresa Beta

A empresa Beta é uma das empresa sólida, que atua no mercado a 20 anos, fez a sua abertura de capital na década de 90 . A relação da empresa Beta com as demais empresas da sua carteira é muito baixa, daí, ao se ter uma empresa da carteira influenciada por algum movimento da economia, a empresa Beta irá sofrer uma interferência mínima neste processo. Ela atua num setor que sofre pouca interferência externa e seus produtos são bem aceitos no mercado nacional.

OBSERVAÇÃO IMPORTANTE: A presente pesquisa utiliza apenas dados fictícios, os dados aqui apresentados não têm nenhuma relação com a realidade.

A partir de informações divulgadas na mídia, é descoberto que a:

Empresa Beta financia campanhas eleitorais, desde a década de 90, na campanha de 2010 para presidência da república ela financiou o partido vencedor. Após o início do governo ela conseguiu contratos novos e que geraram um lucro acima do esperado. E em decorrência destes fatos, analistas políticos, imaginam que provavelmente a empresa Beta será convocada a no próximo ano (2014) financiar da campanha presidencial do partido. 11. Após a descoberta, Eu MANTENHO a indicação da empresa Beta para compor a carteira de investimentos. *

Marcar apenas uma oval. 1

Discordo fortemente

Concordo fortemente

Passados dois meses da descoberta anterior, o mercado através da mídia impressa sabe que 
A empresa Beta, teve uma importante parcela de seu capital adquirida por dois fundos de pensões de empresas estatais. A consequência desta aquisição é que, como na assembléia que acontecerá no próximo mês, estes dois fundos de pensões estatais irão indicar 50\% do Conselho de Administração e a presidência da empresa.

12. Você como analista de investimentos, qual a sua atitude? *

Marcar apenas uma oval.

Retira a empresa do portfólio

Mantém a empresa do portfólio.

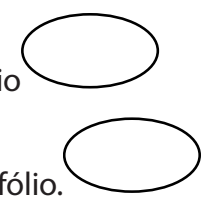

Cadastrar email

13. Se desejar receber o resultado desta pesquisa cadastre seu e-mail abaixo 